\title{
Robotic bees for crop pollination: Why drones cannot replace biodiversity
}

\author{
Simon G. Potts ${ }^{\mathrm{a}, *}$, Peter Neumann ${ }^{\mathrm{b}}$, Bernard Vaissière ${ }^{\mathrm{c}}$, Nicolas J. Vereecken ${ }^{\mathrm{d}}$ \\ ${ }^{a}$ Centre for Agri-Environmental Research, School of Agriculture, Policy and Development, Reading University, Reading RG6 6AR, UK \\ ${ }^{\mathrm{b}}$ Institute of Bee Health, Vetsuisse Faculty, University of Bern and Agroscope, Schwarzenburgstrasse 161, CH-3097 Bern, Switzerland \\ ' Institut National de la Recherche Agronomique (INRA), UR406 Abeilles E' Environnement, 228 route de l'aérodrome, F-84914 Avignon Cedex 9, France \\ d Agroecology Lab, Interfaculty School of Bioengineering, Université libre de Bruxelles (ULB), Boulevard du Triomphe CP 264/2, B-1050 Brussels, Belgium
}

\section{A B S T R A C T}

The notion that robotic crop pollination will solve the decline in pollinators has gained wide popularity recently (Fig. 1), and in March 2018 Walmart filed a patent for autonomous robot bees. However, w present six arguments showing that this is a technically and economically inviable 'solution' at present and poses substantial ecological and moral risks: (1) despite recent advances, robotic pollination is far from being able to replace bees to pollinate crops efficiently; (2) using robots is very unlikely to be economically viable; (3) there would be unacceptably high environmental costs; (4) wider ecosystems would be damaged; (5) it would erode the values of biodiversity; and, (6) relying on robotic pollination could actually lead to major food insecurity.

Throughout the Anthropocene, biodiversity has underpinned a wide range of ecosystems goods and services providing multiple benefits to people and improving human wellbeing (Díaz et al., 2015). Often these services are unrecognized or perceived to be 'free' (Daly and Farley, 2010), and the increasing threats to their ongoing provision poses major challenges for society on how to protect and manage biodiversity (Global Biodiversity Outlook 4, 2014).

Nature has elegantly solved many problems, and scientists and engineers can learn a great deal by studying biodiversity and nature. For instance, the growing field of biomimicry, and its many success stories, is a direct testimony of how innovative engineering solutions derived from the study of adaptations in the natural world can benefit our societies from transport to architecture, swimsuits or even military camouflage (Benyus, 2002). Prototype robots are being developed as autonomous weeding machines for agricultural crops (Reuters, 2018). A recent study by Harvard researchers Chechetka et al. (2017), and the breaking news of Walmart filing a patent for autonomous robot bees (Business Insider, 2018), both propose bringing together the fields of biomimetic science and miniature robotics to address the looming crop pollination crisis as the need for insect pollination increases while the population of managed and wild pollinator dwindle (Aizen and Harder, 2007; Potts et al., 2016). Public concern for pollinators, and the pollination service they provide, has grown rapidly and a quick 'technological fix' to the problem seems quite appealing, especially when the developers of prototype robotic bees claim that they will be able to safeguard crop pollination in the near future. In contrast, the Intergovernmental Platform on Biodiversity and Ecosystem Services global assessment of

\footnotetext{
* Corresponding author.

URL's: s.g.potts@reading.ac.uk, (S.G. Potts), peter.neumann@vetsuisse.unibe.ch, (P. Neumann), bernard.vaissiere@inra.fr, (B. Vaissière), nicolas.vereecken@ulb.ac.be (N.J. Vereecken).
}

pollinators, pollination and food production (IPBES, 2016) and the Convention on Biological Diversity (CBD, 2018) found no evidence to include robotic bees as a credible response option to loss of pollinators or pollination. In this discussion, we recognise that nature can inspire cutting edge technology, but put forward robust arguments showing that robotic pollination is currently incapable of delivering crop pollination to sustain production on a world scale, and even if the technology was developed sufficiently, then there are strong economic, ecological and social reasons not to pursue this route (Fig. 1). Given the increasing scientific, political and public interest in the plight of pollinators, it is important we separate the evidence-based response options from those which are highly speculative and make unrealistic claims as to their putative effectiveness. The aim of this piece is to present a considered view on the opportunities and risks for securing crop pollination services with and without robotic bees. We highlight that emerging technologies have many beneficial roles to play in society, but in this case there is no justification for needlessly trying to replace a key component of biodiversity which can readily be protected and enhanced.

\section{Despite recent advances, robotic pollination is far from being able to replace bees to pollinate crops efficiently}

While technology is moving in the direction of unmanned flying robots able to make complex decisions, they are still extraordinarily clumsy and unsophisticated compared to real bees. Flowers represent multimodal sensory billboards involving shape, colour, scent and even iridescence that are detected, approached and manipulated by bees for the collection of pollen, nectar and other floral rewards through neurological and behavioural responses that are still poorly understood (Cresswell, 2000). Delivering efficient cross-pollination at the level of species-rich communities of co-occurring plant species, or even in a more homogeneous field of cultivated flowering plants, involves a lot 

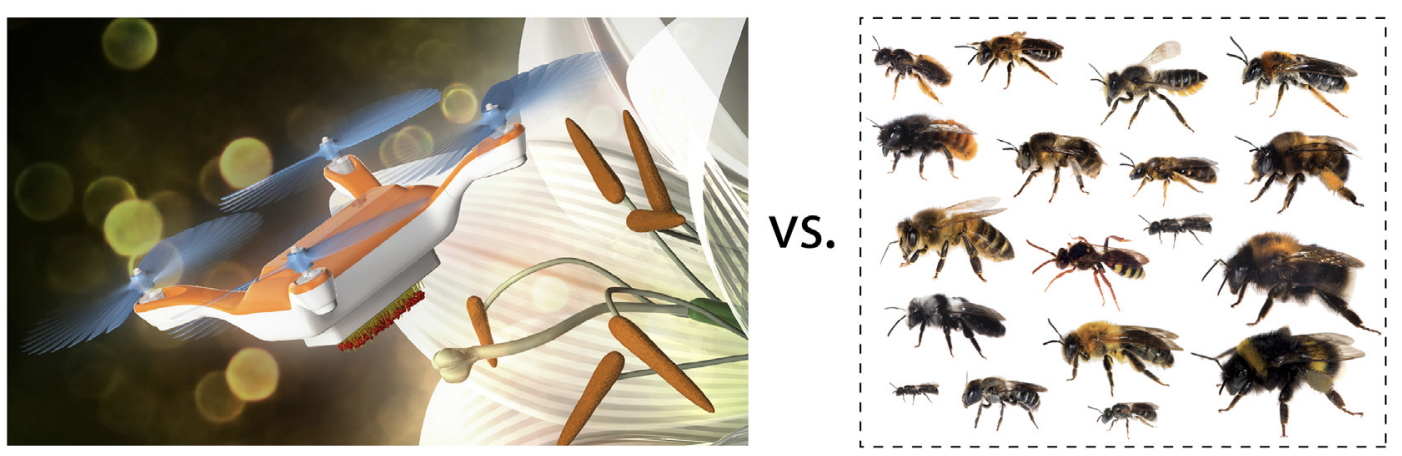

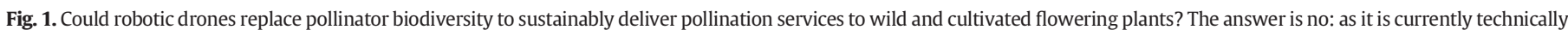
and economically inviable and poses substantial environmental and moral risks. Drone image reprinted from Chechetka et al. (2017) with permission from Elsevier.

more than taking up the technological challenge of designing a miniature drone flying towards a flower and picking up a fraction of the available pollen grains. There are more than 350,000 species of flowering plants on the planet (Ollerton et al., 2011), and they all interact in very unique ways with animals as pollen vectors to bring about sexual reproduction, fruit and seed production, and evolution. Moreover, there are many floral visitors, but only few are actually effective pollinators (King et al., 2013), and their ecological/behavioural traits diversity, not the sheer abundance of one species of particular bee, has been shown to be a significant driver of pollination efficiency and crop yields (Hoehn et al., 2008; Albrecht et al., 2012; Fründ et al., 2013; Garibaldi et al., 2013; Martins et al., 2015). Technology has taken tiny steps to try to address the pollination process of a few 'easy' crops such as sunflowers (Helianthus annuus) which has large disk-shaped easily accessible inflorescence, but is still barely out of the starting gates, while evolution, through the high levels of functional biodiversity and complex ecological, crossed the finishing line millions of years ago.

\section{Using robots is very unlikely to be economically viable}

There are many billions of individual bees and other pollinators across the planet already doing an effective job of crop pollination. Given some of them are declining, the most cost efficient strategy to secure production is to safeguard the pollinators we already have and sustainably manage landscapes to increase their numbers further (IPBES, 2016). Trying to replace this existing pollination service with fleets of robots is economically inviable: even if the technology was up to the job, the cost will likely be totally prohibitive. Even at a modest $\$ 10$ per bee for example, the total cost would be many $100 \mathrm{~s}$ of billions of dollars to pollinate the area of insect-pollinated crops that is currently grown over the world. Further, there are the costs of hardware repair and maintenance, command and control infrastructure. For a fraction of the cost of robot pollination, society could implement well-established solutions (Dicks et al., 2016; IPBES, 2016) to protect pollinator habitats, reduce threats to pollinators and promote biodiversity-friendly cities and landscapes, thereby protecting nature's heroes instead of trying to replace them at exorbitant costs. This is not to say that in the future private individuals and businesses should not invest in developing such technologies for target niches, as it could potentially have a role to play in food production for a small number of specialist crops for which we currently do not have manageable pollinators (such as for hybrid seed production of nectarless crops such as tomato Lycopersicon esculentum or lettuce Lactuca sativa; Liu et al., 2007). Robotic pollinators would likely result in spin-off applications outside pollination, however, to use publically funded research or government subsidies is highly questionable when the outcome is likely to be loss of opportunities to protect existing biodiversity.

\section{There would be unacceptably high environmental costs}

There would be a huge energy, carbon, water and material's footprints to extract, transport and process the raw materials, to manufacture, distribute, and operate, maintain and repair all the robot bees and their associated infrastructure, and to ultimately to dispose of or recycle irreparable or broken robots. For instance, what would be the additional environmental impact of mining all the necessary lithium and other rare earth metals, whose current exploitation is already of growing environmental and social concerns? When robots reach the end of their working lives, or become broken or trapped, what is the fate of all their constituent pollutants entering human and wildlife food chains? Characterising the full energetic and environmental costs of robot bee technology though life cycle assessments (LCAs) will likely reveal a carbon footprint and significant negative impacts on the environment that are all incompatible with our aims for a low-carbon, energyefficient future.

\section{Wider ecosystems would be damaged}

Populating the world with robotic pollinating machines would be a species invasion of epic proportions. It is well-established for pollinators, wild plants and many elements of biodiversity that alien invasive species cause local/regional extinctions, disrupt species interactions networks, as well as ecosystem functions and services (Geslin et al., 2017). Introducing robotic pollinating machines to remove and spread pollen would disrupt the delicate balance of species already in, and reliant on, agricultural and natural ecosystems by displacing existing pollinators, removing pollen forage, while failing to pollinate all the wild flowering plants reliant on biotic pollination (Ollerton et al., 2011).

\section{It would erode the values of biodiversity}

Replacing a key component of biodiversity with a technological alternative, while ignoring opportunities to protect it, fails to take account of the multiple values associated with pollinator biodiversity, such as intrinsic (e.g. inherent worth), social (e.g. beekeeping) and cultural (e.g. aesthetic and recreational) values (IPBES, 2016). For instance, the high social value placed upon monarch butterflies in North America has helped drive conservation actions for this and other threatened species (Diffendorfer et al., 2014). Other innovations, such as robotic weeding machine with precision spraying systems, can significantly reduce the amount of herbicides used by thereby helping support wider biodiversity (Reuters, 2018), which is in stark contrast to pollinating robots aiming to replace biodiversity. 


\section{Relying on robotic bees could actually lead to major food insecurity}

Reliance on a single pollinator is already a high risk strategy for crop pollination (Garibaldi et al., 2013) and the same applies for substituting a diversity of pollinators with robotic devices. While Walmart and others may be proposing new technology to secure supply chains and food production, in reality this approach may increase vulnerability through the failure of complex technology or cyber-attack. Further, low income farmers represent more than 2 billion people reliant on smallholder agriculture in developing nations (Garibaldi et al., 2016), and it is hard to see how these growers will be able to afford robotic pollination services given they struggle to buy even basic agricultural inputs.

Nature is inspirational and we should seek opportunities to learn from millions of years of evolution. But jumping on the popular pollination band wagon, while deliberately overlooking more than 200 years of research on plant-pollinator interactions, by claiming robots can replace bees, or rather "help counter the decline in honeybee populations" (Chechetka et al., 2017) flies in the face of many local, regional, national and international initiatives aiming to safeguard pollinators and their critical values to human well-being (IPBES, 2016). The proposed technology is embryonic, the cost prohibitive, and the wider environmental and societal risks unacceptable.

Risks to crop pollination need to be addressed, and there are a wide range of options open to society going from well-proven practical interventions (e.g. managing habitats to support wild pollinators and/or augmenting populations of managed pollinators), to new food production systems (e.g. ecological intensification of agriculture to embed pollinators into farming, or breed and/or genetically engineer crops that are parthenocarpic or more self-compatible and self-fertile to produce plants less reliant on biotic pollination) (IPBES, 2016; Knapp et al., 2016). There are well developed practices and policies to reduce the immediate risks to pollinators from pesticides, pest and diseases, and climate change, and also more ambitious approaches to transform societies relationship with nature. Together these provide a portfolio of effective tools and solutions to safeguard crop pollination. One has to wonder whether robotic bees simply represent a technological solution desperately looking for a relevant real-world problem to solve. Miniature flying robots, as with other digital technologies, may have many potentially important uses (Arts et al., 2015). Robotic pollination, however, is simply not the answer to securing widespread crop pollination, and encouraging its development diverts time, money, and other resources that could be directed towards national and international pollinator initiatives and policies (Dicks et al., 2016), striving to secure both biodiversity conservation and food production in a sustainable manner.

\section{References}

Aizen, M.A., Harder, L.D., 2007. Expanding the limits of the pollen-limitation concept: effects of pollen quantity and quality. Ecology 88, 271-281.

Albrecht, M., Schmid, B., Hautier, Y., Müller, C.B., 2012. Diverse pollinator communities enhance plant reproductive success. Proc. R. Soc. B 279, 4845-4852.

Arts, K., van der Wal, R., Adams, W.M., 2015. Digital technology and the conservation of nature. Ambio 44, 661-673.

Benyus, J.M., 2002. Biomimicry: Innovation Inspired by Nature. Perennial, New York.

Business Insider, 2018. A Giant US Retail Corporation Just Filed a Patent For Autonomous Robot Bees. Retrieved from:. https://www.sciencealert.com/walmart-has-filed-a-patent-for-robot-bees-pollination-drones.

CBD, 2018. Convention on Biological Diversity, Subsidiary Body on Scientific, Technical and Technological Advice 22nd meeting of SBSTTA "Conservation and Sustainable use of Pollinators", Montreal, Canada, 2018.

Chechetka, S.A., Yu, Y., Tange, M., Miyako, E., 2017. Materially engineered artificial pollinators. Chem 2, 224-239.

Cresswell, J.E., 2000. Manipulation of female architecture in flowers reveals a narrow optimum for pollen deposition. Ecology 81, 3244-3249.

Daly, H.E., Farley, J., 2010. Ecological Economics: Principles and Applications. 2nd edition. Island Press.

Díaz, S., Demissew, S., Joly, C., Lonsdale, W., Ash, N., et al., 2015. The IPBES conceptual framework-connecting nature and people. Curr. Opin. Environ. Sustain. 14, 1-16.

Dicks, L.V., Viana, B., Bommarco, R., Brosi, B., Arizmendi, M.C., et al., 2016. Ten policies for pollinators. Science 354, 975-976.

Diffendorfer, J.E., Loomis, J.B., Ries, L., Oberhauser, K., Lopez-Hoffman, L., et al., 2014. National valuation of monarch butterflies indicates an untapped potential for incentive-based conservation. Conserv. Lett. 7, 253-262.

Fründ, J., Dormann, C.F., Holzschuh, A., Tscharntke, T., 2013. Bee diversity effects on pollination depend on functional complementarity and niche shifts. Ecology 94, 2042-2054.

Garibaldi, L.A., Steffan-Dewenter, I., Winfree, R., Aizen, M.A., Bommarco, R., et al., 2013. Wild pollinators enhance fruit set of crops regardless of honey-bee abundance. Science 339, 1608-1611.

Garibaldi, L.A., Carvalheiro, L., Vaissière, B.E., Gemmill-Herren, B., Hipólito, J., et al., 2016. Mutually beneficial pollinator diversity and crop yield outcomes in small and large farms. Science 351, 388-391.

Geslin, B. Gauzens, B, Baude, M., Dajoz, I. Fontaine, C et al, 2017. Massively introduced managed species and their consequences for plant-pollinator interactions. In networks of invasion: empirical evidence and case studies. Adv. Ecol. Res. 57, 147-199.

Global Biodiversity Outlook 4, 2014. Secretariat of the Convention on Biological Diversity.

Hoehn, P., Tscharntke, T., Tylianakis, J.M., Steffan-Dewenter, I., 2008. Functional group diversity of bee pollinators increases crop yield. Proc. R. Soc. B 275, 2283-2291.

IPBES, 2016. The Assessment Report of the Intergovernmental Science-Policy Platform on Biodiversity and Ecosystem Services on Pollinators, Pollination and Food Production. IPBES, Bonn, Germany.

King, C., Ballantyne, B., Willmer, P.G., 2013. Why flower visitation is a poor proxy for pollination: measuring single-visit pollen deposition, with implications for pollination networks and conservation. Methods Ecol. Evol. 4, 811-818.

Knapp, J.L., Bartlett, L.J., Osborne, J.L., 2016. Re-evaluating strategies for pollinatordependent crops: how useful is parthenocarpy? J. Appl. Ecol. 54, 1171-1179.

Liu, L.-W., Wang, Y., Gong, Y.-Q., Zhao, T.-M., Liu, G., et al., 2007. Assessment of genetic purity of tomato (Lycopersicon esculentum L.) hybrid using molecular markers. Sci. Hortic. 115, 7-12.

Martins, K.T., Gonzalez, A., Lechowicz, M.J., 2015. Pollination services are mediated by bee functional diversity and landscape context. Agric. Ecosyst. Environ. 200, 12-20.

Ollerton, J., Winfree, R., Tarrant, S., 2011. How many flowering plants are pollinated by animals? Oikos 120, 321-326.

Potts, S.G., Imperatriz-Fonseca, V., Ngo, H.T. Aizen, M.A., Biesmeijer, J.C, et al, 2016. Safeguarding pollinators and their values to human well-being. Nature 540, 220-229.

Reuters, 2018. Robots fight weeds in challenge to agrochemical giants. Retrieved from:. https://www.reuters.com/article/us-farming-tech-chemicals-insight/robots-fightweeds-in-challenge-to-agrochemical-giants-idUSKCN1INOIK. 